\title{
Field Investigation and Comparison Analysis of Low-Grade Heat Pump Technologies in Building Space Heating Projects
}

\author{
Yanxue Li ${ }^{1, *}$, Weijun Gao ${ }^{1,2}$, Xiaoyi Zhang ${ }^{2}$, Wenya $\mathrm{Xu}^{1}$, Yingjun Ruan ${ }^{3}$ and Yinzhong Wang ${ }^{4}$ \\ ${ }^{1}$ Innovation Institute for Sustainable Maritime Architecture Research and Technology, Qingdao University of Technology, Qingdao, \\ 266033, China \\ ${ }^{2}$ Faculty of Environmental Engineering, The University of Kitakyushu, Kitakyushu, 808-0135, Japan \\ ${ }^{3}$ Institute of Mechanical Engineering, Tongji University, Shanghai, 200092, China \\ ${ }^{4}$ Dongying Electric Power Company, Dongying, 257000, China \\ *Corresponding Author: Yanxue Li. Email: liyanxue@qut.edu.cn
}

Received: 17 February 2021 Accepted: 18 June 2021

\begin{abstract}
The building sector contributes a large ratio of final energy consumption, and improving building energy efficiency is expected to play a significant role in mitigating its carbon dioxide emission. Herein, we collected the on-site measurement data to investigate the techno-economic performances of different heat pump types that exist in building space heating projects in Qingdao, China. An in-depth analysis revealed the temperature variations of measured low-grade heat sources over the whole heating supply period, and urban sewage water shows high stable heat energy quality compared with seawater and geothermal heat resources. Operational behaviors including cycling inlet and outlet temperature of the selected heat pumps were illustrated, and analysis evaluated detailed effects of operational parameters on energy efficiency performances. Then the relationship between COPs distributions of heat pumps and operational conditions was examined further, and the positive effect of the rising temperature of heat sources on energy efficiency improvement of heat pump is highlighted when the heating supply temperature is higher. Furthermore, we analyzed the economic and carbon emission performance of the heat pump system, and results show that electricity price plays a vital role in the lifespan energy cost saving potential, and the heat pump could serve as a promising approach in reducing $\mathrm{CO}_{2}$ related to the building space heating. Finally, we recommended suggestions for improving the overall energy efficiency and cost competitiveness of decentralized heat pump systems for building space heating.
\end{abstract}

\section{KEYWORDS}

On-site measurement; heat pumps; heating supply; operational performance

\section{Introduction}

The building sector accounts for a large proportion of final social energy consumption, and the energy efficiency improvement of district heating is expected to play a key role in mitigating carbon dioxide emission [1,2]. For instance, China has undergone rapid industrialization and urbanization since 1980, the building energy consumption experienced a steady growth. According to the Annual Report on China Building Energy Efficiency 2020 [3,4], energy consumption for building construction and operation 
shared around $37 \%$ of the social energy usage in 2018 , and central building heating energy consumption in north China is responsible for around $20 \%$ of total energy consumption in 2018 . The carbon dioxide emission from building sector presents a continuous rising trend and is expected to reach the peak value in around 2040. It may create significant challenges as the Chinese government's commitment for carbon dioxide emissions to peak by 2030 or making best efforts to peak earlier [5].

The current urban large-scale district heating network is mainly supported by centralized coal-fired heat boiler or combined heating and power plant in China, the energy consumption in district heating increased has tripled over the last decades, and heat energy loss in primary heating network is large due to the high domestic hot water supply temperature and long transmission distance [6]. Meanwhile, fossil fuel burning related fine particulate matter (PM2.5) has brought serious challenges to environmental protection in China, especially when the annual urban central heating supply period begins [7]. Meanwhile, in order to encourage the sustainable development, financial incentives offered by the local government has accelerated the deployment and reform of the "Clean Heating", exploitation of alternative heat resources is expected to play a crucial role in achieving low-carbon heating supply [8]. Meanwhile, the government also pays rising attention to explore energy efficiency measures in heating sector, including technology innovations and relevant subsidies $[9,10]$. Heat pump is recognized as one of the promising solution that have attracted increasing attention for realizing energy efficiency in building space heating. Heat pump has been strongly pursued and their installed capacity increased rapidly in China [11-13].

\section{Literature Review}

In order to make district heating system more energy efficient and flexible, there is a transition toward bidirectional lower temperature networks design in 5th Generation District Heating [14], lower temperature heating system has two implications: improved opportunities to exploit alternatives of low-grade heat sources and less distribution loss that generates heat in close to the end-user [15]. The decentralized lowtemperature heating supply system has been widely investigated and applied for the reduction of primary energy consumption [16].

Numerous studies have conducted the modeling design [17], simulation analysis [18] and field test [19] of different heat pump technologies. As temperature-dependent heating upgrading technologies, the energy efficiency of heat pump highly depends on the availability and quality of low-grade heat sources. The heat pump system could extract heat energy from air, water and ground source during the operation process, its overall performance highly depends on the operational conditions [20,21]. In order to achieve costeffectiveness application of heat pump in building heating, a stable heat source is important [22,23]. Commercial air source heat pumps had gained popularity for space heating or hot water supply in the residential sector over recent decades due to the simple operation and low maintenance cost [24]. However, its coefficient of performance (COP) might drop sharply with the decreasing of the ambient temperature $[20,24]$. Cold air would reduce the heating capacity of the air source heat pump and lead to unreliable heating generation [25]. Thus, it would be less cost-competitiveness [26], even shorten the lifespan of the compressor in cold region application, due to the frost over the evaporator and large compression ratio [27,28]. To overcome the shortcoming, a combination of heat pumps and solar thermal systems also have been studied in relevant literature [29,30]. However it is important to optimize the size of the components, it would cause a cost burden for the user due to over-sized capacity or low annual load factor [18]. The exploitation of alternative heat source such as water and geothermal have attracted significant attention.

A geothermal heat pumps could be considered as a renewable energy system, mainly because of their use of geothermal energy [31]. And it could perform efficiently when the depth of heat take is enough 
due to the stable thermal property of the soil [32]. Meanwhile, with continuous capital cost drop and efficiency improvement, geothermal source heat pump is also expected to deliver significant cost savings compared with traditional district heating [33]. It is also worth noting that the decrease in annual mean temperature of the ground becomes is negligible after long-term operation of the heat pump in heating supply mode [34]. Field measurement has found that more heat extraction than rejection leads to falling tendency of ground source water temperature [19]. Therefore, in order to maintain the energy efficiency of the ground source heat pump, balance the seasonal loads of the borehole heat exchanger is essential [35].

The seawater heat pump could be used for domestic heating or cooling supply in coastal cities, and its applications in Sweden, Norway and China were widely reported [11]. However, its expansion is highly constrained by geographical availability, seawater temperature is sensitive to the ambient temperature, a stable heat source is also a concern for successful application of seawater heat pump [36]. Meanwhile, corrosion and microbial attachment on heat exchanger may worsen the heat extraction ability of the heat pump unit. Seawater temperature is a critical factor influencing the energy efficiency of the heat pump, it is also important to prevent freezing when the outside is severely cold [37,38]. In order to extract heat more reliable, researchers suggested renovations in the heat exchange process [37,39].

Urban sewage water is generally composed of bathing, cooking and cleaning, etc., and the temperature is high due to the urban domestic and industrial activities. The temperature value of wastewater is generally not lower than $10^{\circ} \mathrm{C}$ in heating period, there existed the great potential for heat recovery [40]. For example, urban wastewater temperature could be $20^{\circ} \mathrm{C}$ higher than the ambient temperature during the winter period in Beijing, China, and almost $40 \%$ of the urban produced heat is sent to the sewerage system as waste heat [41]. Harnessing heat of reclaimed water from the sewage treatment plant is becoming a sustainable choice for the development of energy-efficient heat pump. Urban sewage water contains considerable thermal energy and its annual flow rate remains almost constant, which can play a positive role in the efficiency improvement of the heat pump [42]. Compared with other type of heat pumps, the wastewater heat pumps could run efficiently due to the relatively stable and high temperature of the waste heat source, especially when the outdoor temperature is low and the heat load is large [43]. However, it is also worth noting that prime mover, pipeline and space construction in the substation would cause high initial investment, it may be more suitable or constrained for large-scale heating supply application.

The heating capacity of different heat pumps varies with the weather condition during the heating period, COP of the heat pump would be highly influenced by the temperature lift, and quality of heat sources and annual utilization ratio would play crucial role in influencing energy and economic feasibility of heat pump applications [44]. However, practical heating system operation is rarely monitored and compared in detail. Regarding the promotion of heat pump competitiveness for building space heating, it is essential to help the energy operator or manager to acquire a better understanding of how and what extent the heat pumps different in real-world operations, the field measurement is required to compare and evaluate heat pump technologies explicitly, further propose possible recommendations.

The aim of this study is to assess and compare the operational performances of different real-world heat pump technologies in existing building heating supply projects. Firstly, we presented detail thermodynamic behaviors of examined heat pump technologies, thermal quality of heat source and effects of operating condition on performances of heat pumps were compared based on the measured data. Then revealed the detailed thermodynamic behaviors of the heat pumps, as well as power consumptions and COPs under various situations. After that, a sensitive analysis of heat pump was carried out from the NPV performance and carbon emission reduction perspective. Finally, we discussed the obstacles and problems existing in real-world heat pump applications, provided insights for improving heat pump performance. 


\section{Objective and Methodology}

\subsection{Objectives and Datasource}

Qingdao is the largest city in Shandong Province, North China, which features a long coastal line, the average outdoor temperature is $-0.5^{\circ} \mathrm{C}$ in January (the coldest month) that belongs to the cold zone, Fig. 1 presents the geological location of the research objectives. The current primary pipe network of Qingdao urban central heating supply system mainly extracts $80-100^{\circ} \mathrm{C}$ hot water from the central large thermal power plant, then pumps hot water from the secondary heat exchange station to terminal heating devices (i.e., radiators and floor heating coil) that set-point temperature is around $50^{\circ} \mathrm{C}$. It provides a favorable chance for heat pump as heat alternative for building heating supply. Different heat pump technologies had been implemented for residential, office and commercial space heating in Qingdao City.

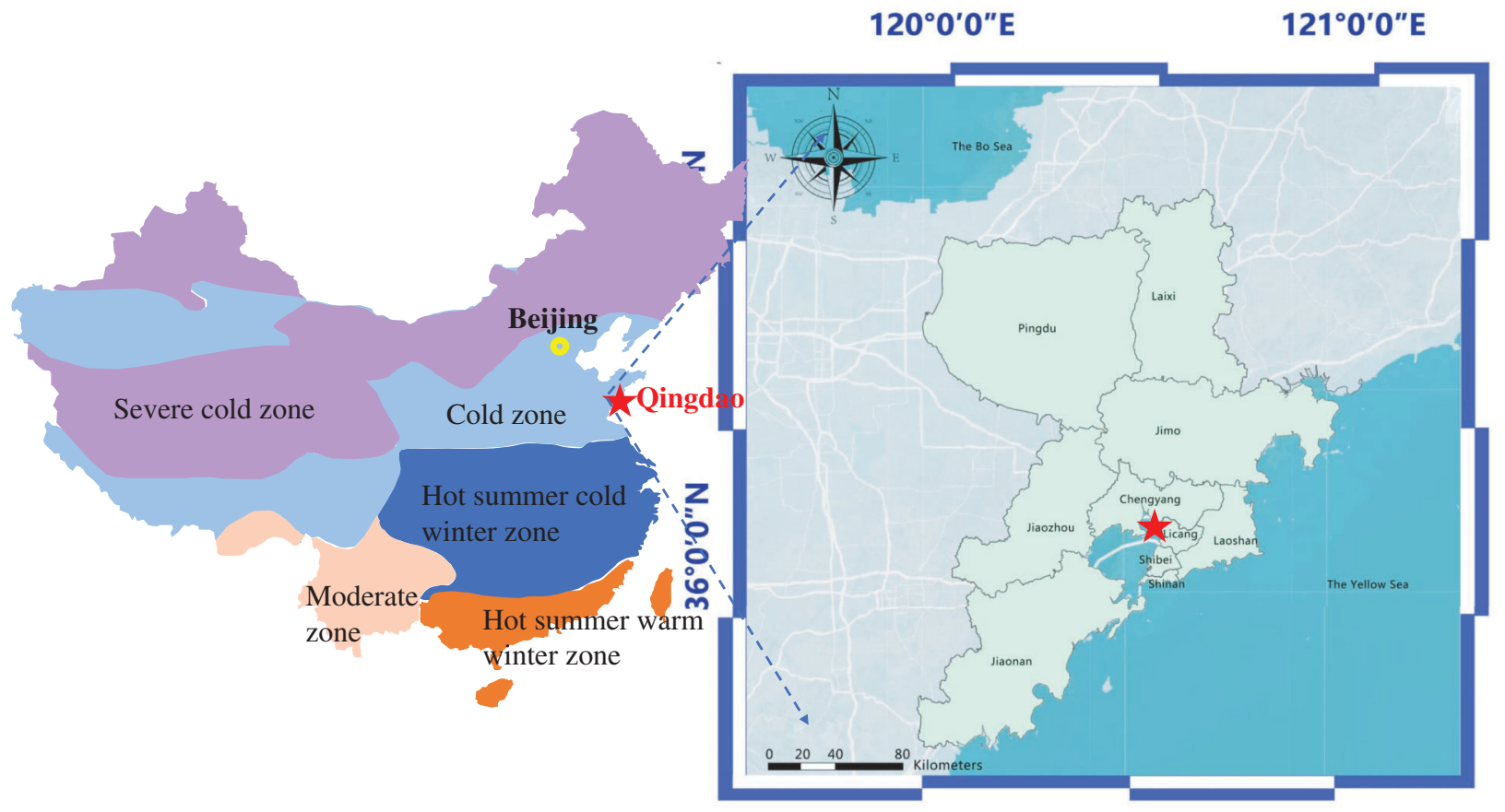

Figure 1: Geographic and climate condition of study site

The photograph of selected measured heat pump projects and monitoring platform is shown in Fig. 2, the measuring transducers were installed on-site that measure circulating water temperatures, volumetric flow rates in supply and user sides, as well as electricity consumption. Fluid temperature is measured by PT100 with $\pm 0.3^{\circ} \mathrm{C}$, the uncertainties of flow meter and electric consumption meter are both $\pm 1.5 \%$. Measured data would be automatically recorded by the data acquisition system and transmitted via the Internet of things to the building energy consumption and renewable project monitoring platform. Data including heat source and hot water supply temperatures, water mass flow rate as well as electricity consumption were obtained at 15 min intervals from the monitoring platform. The measurement period lasted from 6th November of 2014 to 6th April of 2015, which covers the whole heating season.

\subsection{System Description}

The schematic diagram of the heat pump heating supply system: heat pump unit, outdoor and indoor parts as shown in Fig. 3. Heat pumps extract heat from heat sinks including outdoor wastewater, seawater or groundwater at evaporator part, then releases the heat energy to the buildings through water circulating cycle, The temperature of inlet heating source and hot water supply play as critical factors influencing the operational performances of heat pumps. In the field measurement, thermal flow can be obtained by multiplying temperature differences and real-time water flow rate, power meters monitor simultaneously 
electrical consumption. Basic information of measured heat pump projects was listed in Table 1, buildings feature with different area, indoor side installed radiant floor heating or air handling unit terminal.
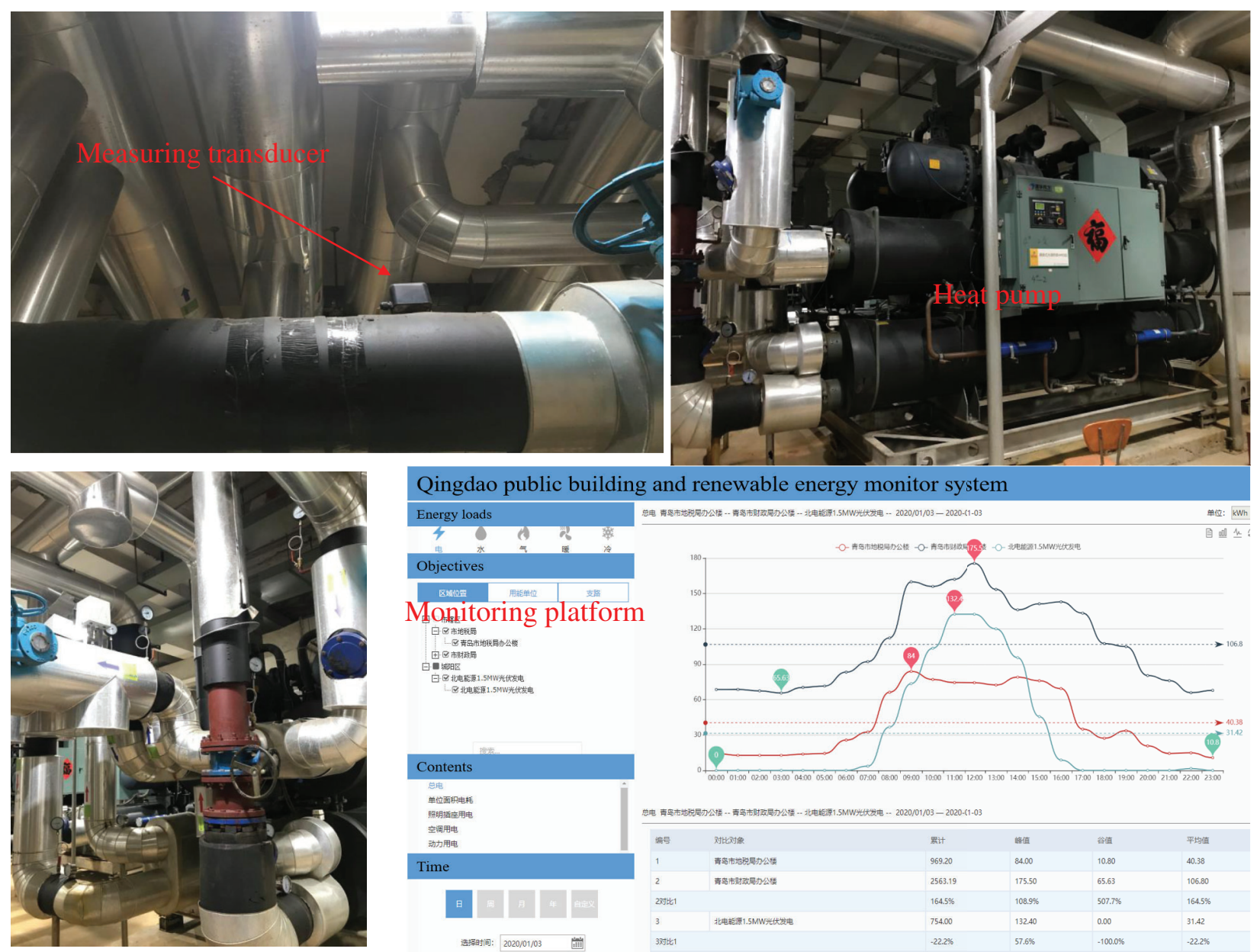

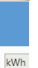

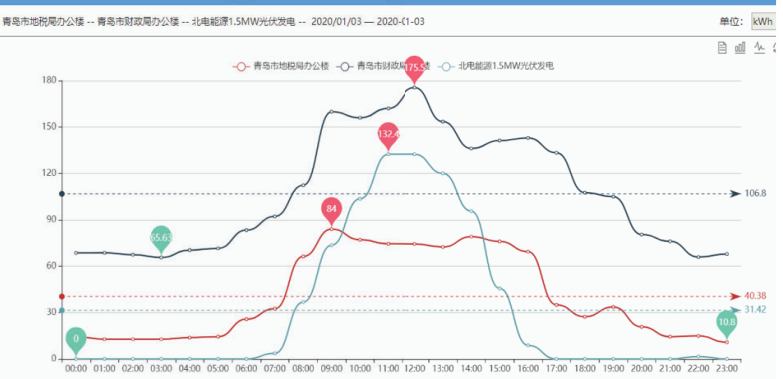

Figure 2: Scene of the measured heat pump system and monitoring platform

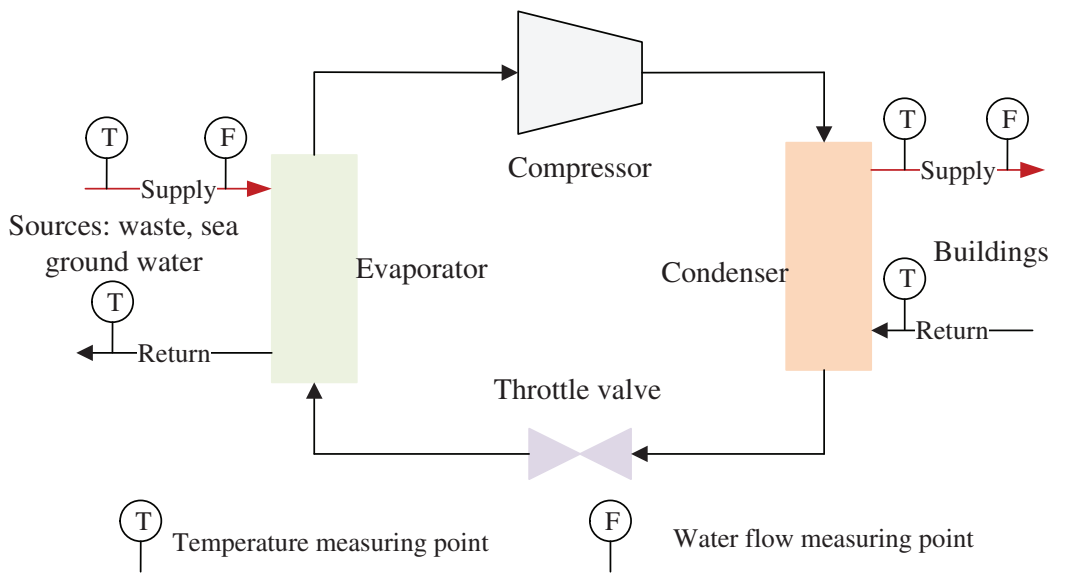

Figure 3: Schematic diagram of monitored heat pump district heating systems 
Table 1: Basic information of field measured heat pump projects

\begin{tabular}{|c|c|c|c|}
\hline Variables & Project 1 & Project 2 & Project 3 \\
\hline \multicolumn{4}{|l|}{ Building exterior } \\
\hline Building type & Residential & Hotel & School \\
\hline Building area $\mathrm{m}^{2}$ & 250000 & 18200 & 9770 \\
\hline Heat sources & Sewage water & Seawater & Geothermal \\
\hline $\begin{array}{l}\text { Heat transfer } \\
\text { coefficient of } \\
\text { exterior wall, W/ } \\
\left(\mathrm{m}^{2} . \mathrm{K}\right)\end{array}$ & 0.50 & 0.60 & 0.55 \\
\hline $\begin{array}{l}\text { Area ratio of } \\
\text { window to wall }\end{array}$ & 0.30 & 0.65 & 0.35 \\
\hline $\begin{array}{l}\text { Terminal heating } \\
\text { device }\end{array}$ & Radiant floor & Air handling unit & $\begin{array}{l}\text { Radiant floor }+ \\
\text { Air handling unit }\end{array}$ \\
\hline
\end{tabular}

\section{Result and Discussion}

\subsection{Heat Quality Comparison}

The time-series temperature profiles of the selected heat sources during the heating period were shown in Fig. 4. The ambient temperature varied significantly over the heating period, and it varied both in magnitude and variance. The temperature decreasing and rising trend of the test heat sources including wastewater, seawater and ground source water tracked the variation of ambient temperature. Seawater temperature decreased more under lower ambient temperature, wastewater temperature exhibited most stable and high thermal properties, the absent data value in ground source temperature profile presents school holiday period that heat pump stopped.

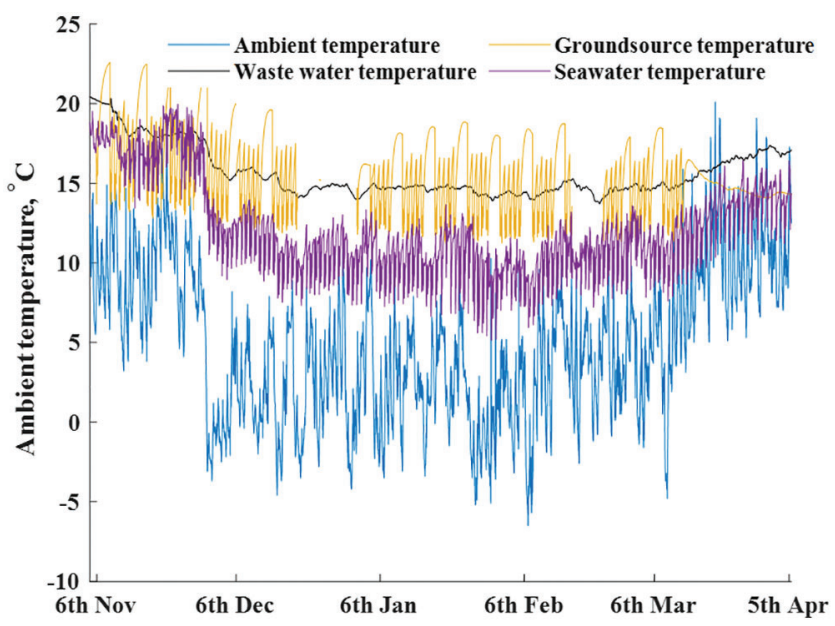

Figure 4: Measured temperature profiles of ambient air, wastewater, seawater and ground sides during the whole heating period 
Fig. 5 depicted the daily temperature profiles of heat pumps' evaporator inlet, the temperature variations shown a close relationship with their scheduling schemes of heat pump systems. The temperature distributions of measured seawater and groundwater had a close relationship with occupancy of the buildings during the day, and temperatures of seawater and ground sides experienced an obvious drop when the heat pump operated. Blank and daily uniform distribution part in the ground source presents the holiday period that heat pump system had shut down. Operation of seawater heat pump had shaped the periodic valley period that concentrated at noon and an early night, it was more obvious in colder days. Wastewater heat pump for residential space heating operated continuously throughout the day, the inlet temperature of wastewater remained stable and constant, seawater temperature fluctuated more with the change of ambient temperature, even in a daily period. Fig. 6 compared the variations and ranges of measured outdoor and heat resources temperatures at specific 12:00 AM of each day that corresponds to the all running time of selected heat pumps, the maximum, minimum and average temperature at the inlet of evaporator were clearly observed during the whole heating supply period. Seawater temperature fluctuated more with the variation of the outdoor temperature. Urban wastewater exhibited as the most stable heat source compared with other heat resources, its lowest temperature was the highest among the heat sources, indicated wastewater is more thermal resistant to variations of ambient temperature.
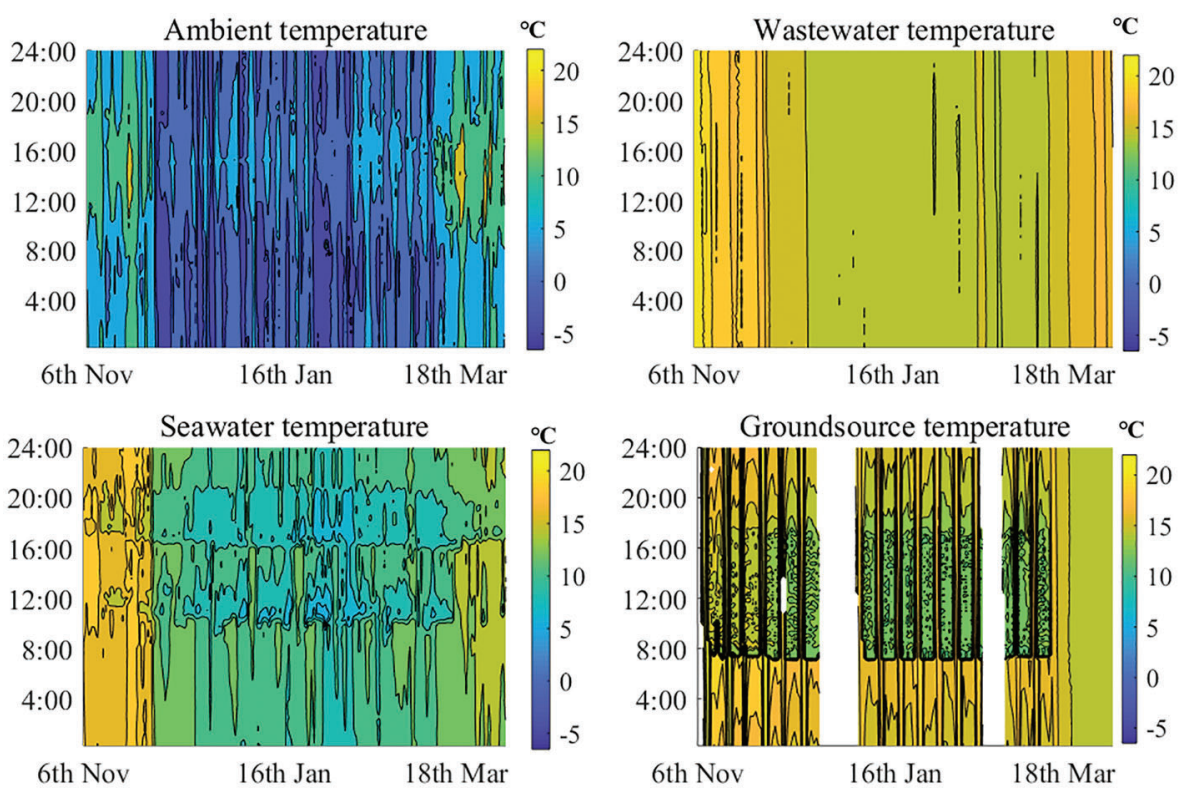

Figure 5: Daily distribution of ambient temperature and inlet temperature at evaporator inlet of selected heat pumps during whole heating season

\subsection{Thermodynamic Behaviors}

Heating load and operating conditions have significant effects on the overall energy efficiency of heat pump systems. Figs. 7 and 8 displayed the dynamic characteristics of water flow velocity at the supply and user sides of selected heat pumps, respectively. Wastewater heat pump and geothermal heat pump presented an intermittent running mode that depends on their occupancy scenarios, their water mass flow remained almost constant during the whole heating season. Relatively slow flow velocity in ground side may be attributed to the low thermal transfer efficiency between soil and pipeline.

Hot water supply temperature plays a crucial role in meeting variable heating demand, heat pumps mainly adjust suitable supply temperature to meet variable building heat demand during the whole 
heating period. Wastewater heat pump operated continuously for residential heating supply, heating supply temperature dependency on outside temperature is shown in Fig. 9. It is possible to maintain residential indoor thermal comfort at lower water supply temperature under higher ambient temperature, the measured heating supply temperature presented a linear rising trend with decreasing ambient temperature, the maximum constraints would be compensated on the required supply temperature when the ambient temperature decreased further.

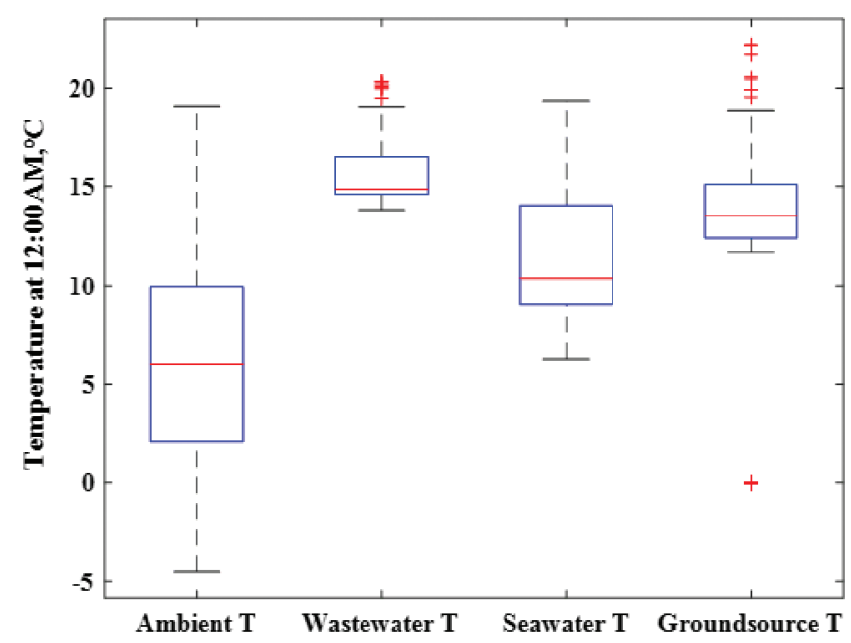

Figure 6: Boxplot for ambient temperature and inlet temperature of heat pumps' evaporators

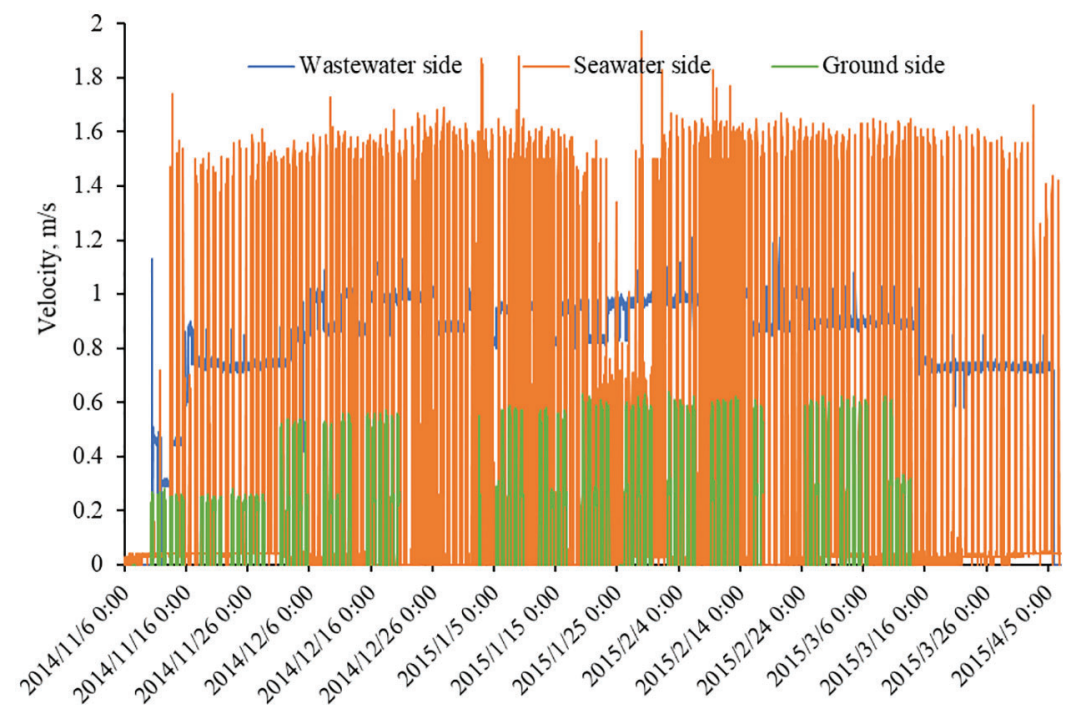

Figure 7: Measured velocity of water flow at evaporator side

As described in Figs. 10-12, the blue and orange lines present dynamic inlet and outlet temperatures at the evaporator part measured at 15 min intervals, respectively. As shown in Fig. 10, the temperature of the wastewater supply remained $14.4^{\circ} \mathrm{C}$ approximately, which exhibited as a relatively stable heat source. The daily cycling pattern of seawater temperature profile had a close relationship with business hours of hotel mainly opening for lunch and dinner as illustrated in Fig. 11. We could observe the sharp drop in outlet 
seawater temperature when the heat pump started up in the afternoon, around $3.5^{\circ} \mathrm{C}$ temperature step occurred from $15: 45$ to $16: 00$, and the weekly range of supply temperature varied from 11.6 to $5.9^{\circ} \mathrm{C}$, it fluctuated more during an operating time and its average value was lower compared with wastewater and ground source water. Fig. 12 illustrated how the temperature of water from the ground source varied over a day, with the continuous heat extraction from the soil, there is a gradual temperature decrease of supply temperature at the evaporator that associated with the time when the heat pump started to operate. The measured maximum and minimum temperatures of supply water were 15.6 and $12.8^{\circ} \mathrm{C}$, respectively. The temperature of the ground source would rise smoothly when the heat pump shut off and finally reached a stable balanced condition at weekend, that the heat extraction from the soil was continuous and finally reached the balanced scenario between the soil and ground pipe.

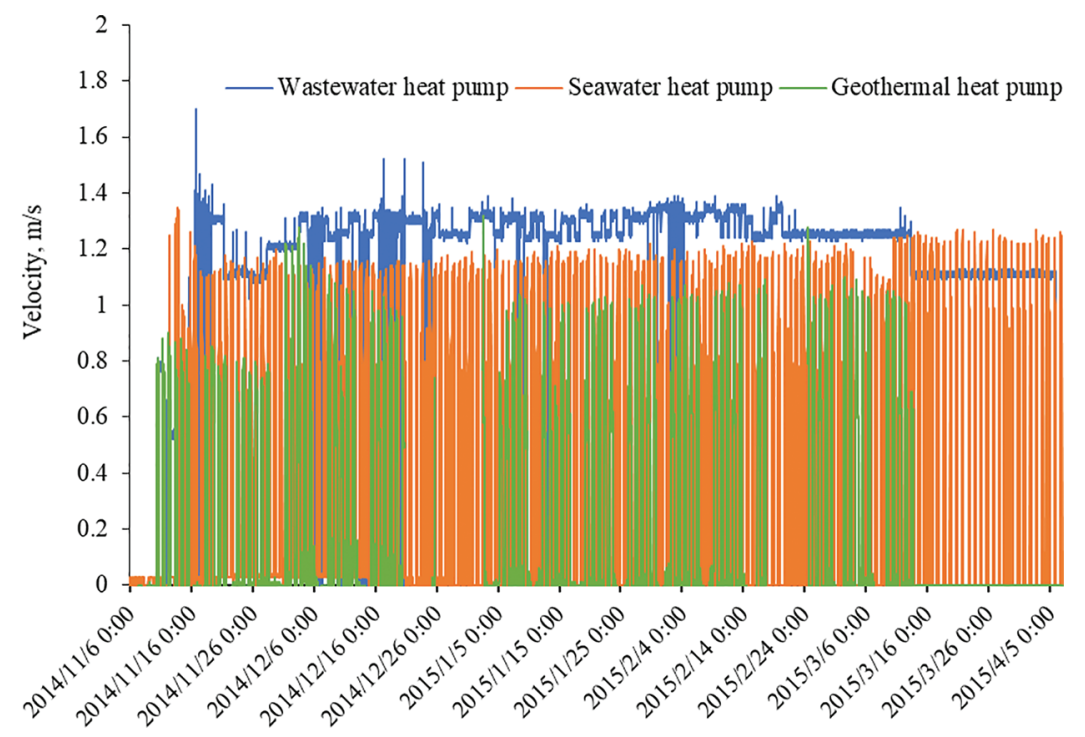

Figure 8: Measured flow velocity at condenser side

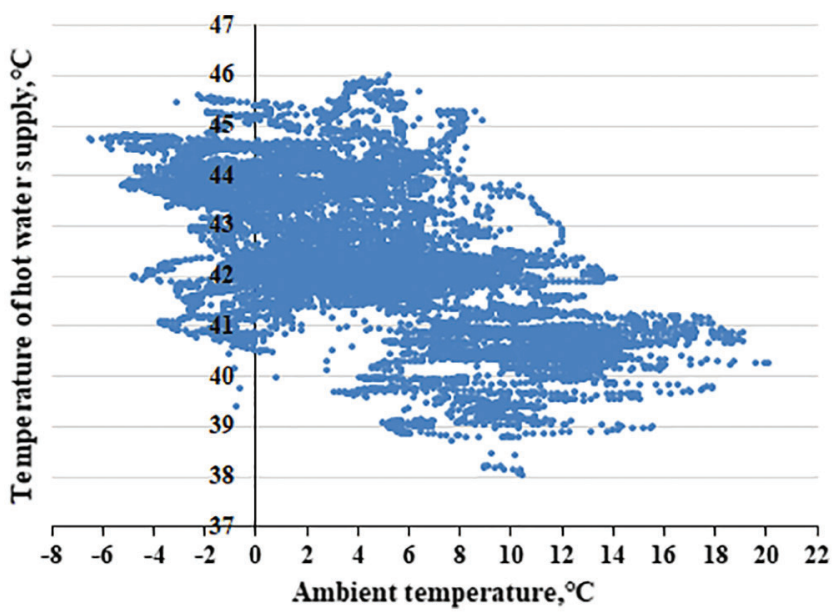

Figure 9: Scatter distribution of measured heating supply temperature of wastewater heat pump with outdoor temperature 
EE, 2022, vol.119, no.1

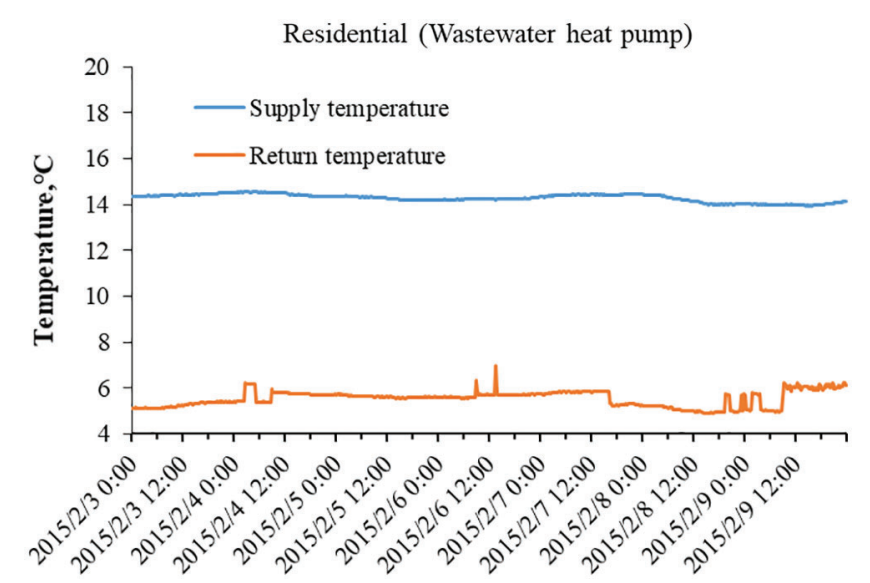

Figure 10: Temperature distribution of cycling water in evaporator of wastewater heat pump from 3th February to 9th February of 2015

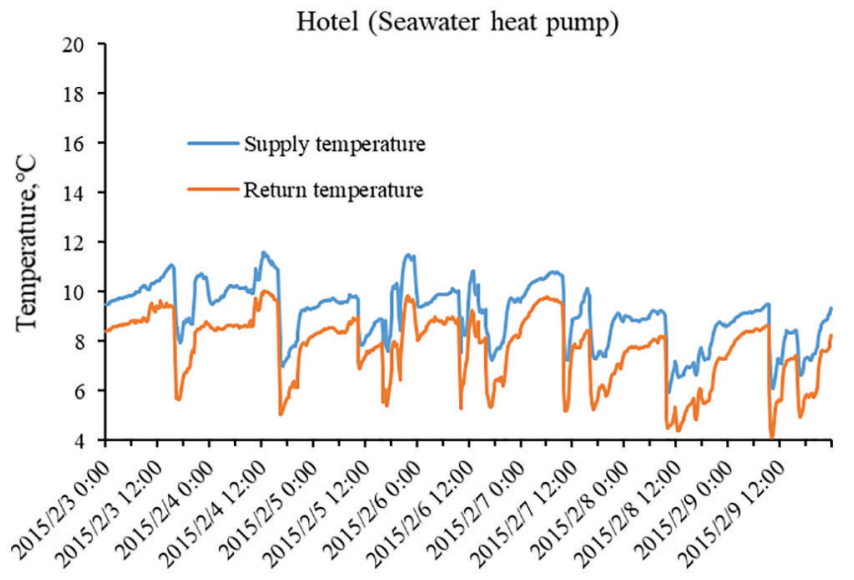

Figure 11: Temperature distribution of cycling water in evaporator of seawater heat pump from 3th February to 9th February of 2015

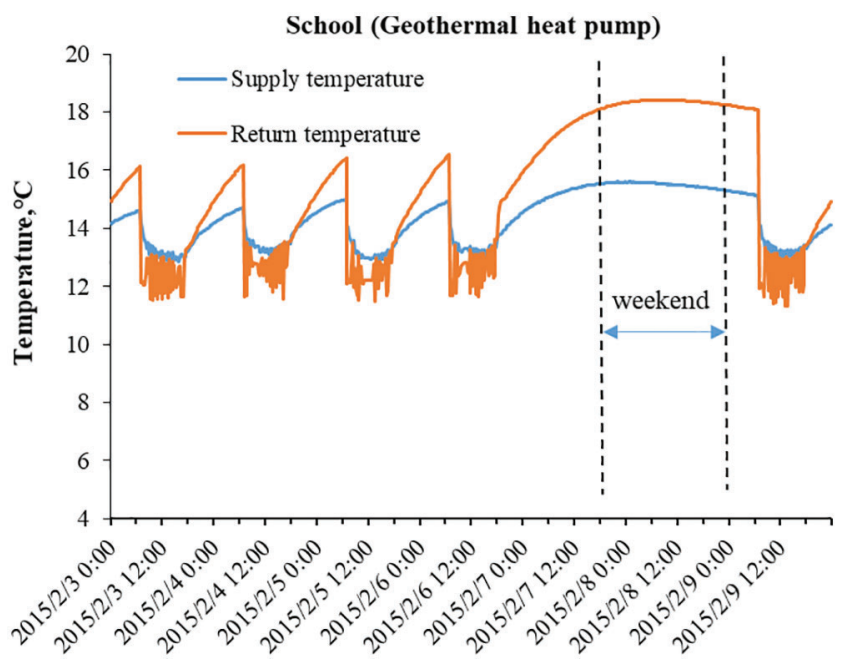

Figure 12: Temperature distribution of cycling water in evaporator of geothermal heat pump from 3th February to 9th February of 2015 


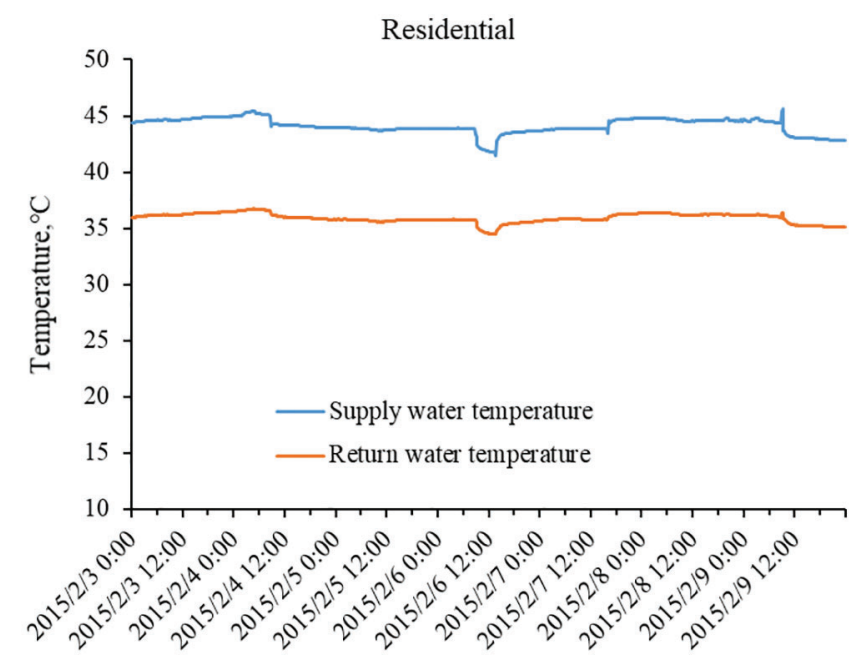

Figure 13: Temperature distribution of cycling water in condenser of wastewater heat pump from 3th February to 9th February of 2015

In order to clearly observe scheduling characteristics of heat pumps, Fig. 13 shown thermal dynamic cycling behaviors of the outlet and inlet water temperature in the wastewater heat pump's condenser part. Residential floor heating radiator device enabled lower return temperature to meet thermal comfort in residential buildings. And there existed a relatively stable and larger temperature difference between the supply and return temperature of hot water at the condenser part. The temperature difference in user side and operation period was less in hotel and school as displayed in Figs. 14 and 15. They featured higher return temperature from the user side, these scenarios may be owing to the radiator type, hydraulic and thermostat control of the heating system.

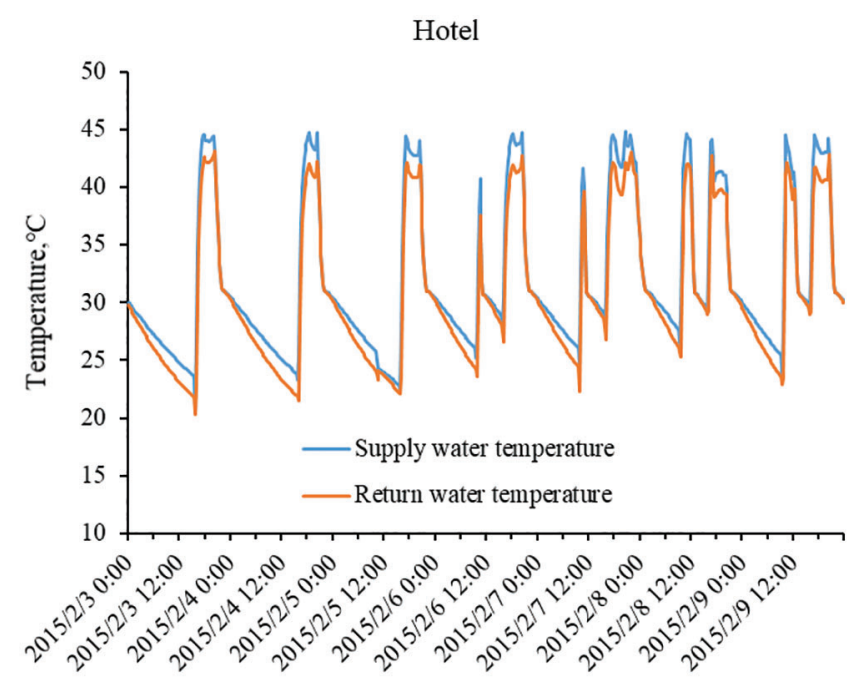

Figure 14: Temperature distribution of cycling water in condenser of seawater heat pump from 3th February to 9th February of 2015 
EE, 2022, vol.119, no.1

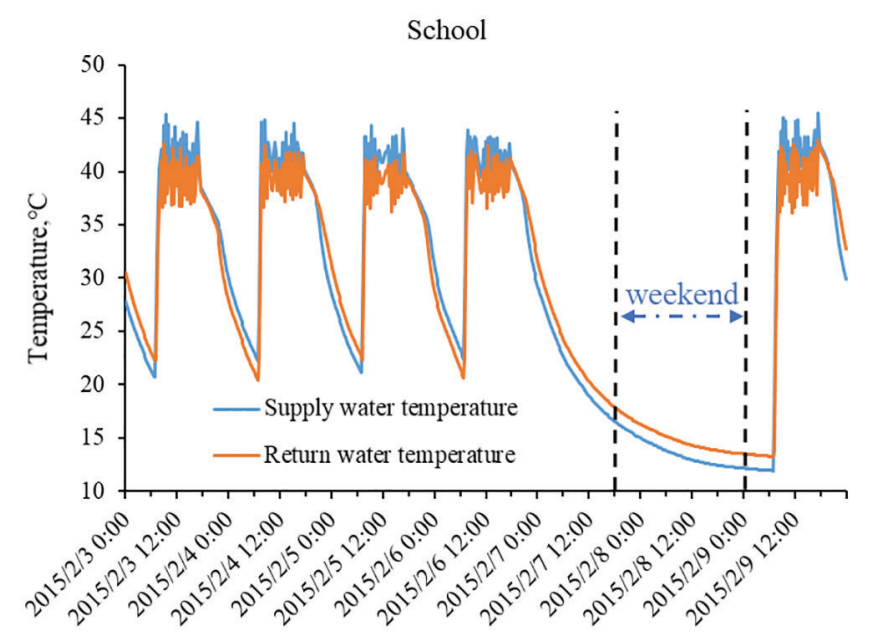

Figure 15: Temperature distribution of cycling water in condenser of geothermal heat pump from 3th February to 9th February of 2015

The COP of the heat pump unit is defined as the relationship between thermal output and electricity input under the heating condition:

$C O P=\frac{Q}{W}$

$Q=\frac{1}{3600} m \cdot c_{p} \cdot\left(T_{s}-T_{r}\right)$

where, $\mathrm{m}$ is the mass flow rate in user side, $\mathrm{kg} / \mathrm{s} ; c_{p}$ is water specific heat, $\mathrm{kJ} /\left(\mathrm{kg} \cdot{ }^{\circ} \mathrm{C}\right)$; $T_{s}$ is supply temperature, ${ }^{\circ} \mathrm{C}$; $T_{r}$ refers to return temperature, ${ }^{\circ} \mathrm{C}$; $\mathrm{Q}$ is the heating load of heat pump unit, $\mathrm{kW}$; W is input power of the unit, $\mathrm{kW}$.

The weekly heating and COP profiles of heat pump units at 60-min interval were calculated and displayed, as shown in Figs. 16 and 17. The average value of the COPs during this period for wastewater, seawater and geothermal heat pumps reached 7.3, 5.3 and 4.4, respectively. The dynamic characteristics of measured COPs presented close relationships with their on-off schedule strategies, heating COPs of seawater and ground source heat pump exhibited considerable fluctuations during their daily operating period, at the early stage of the period the value was higher, then it presented a dropping trend. The COPs of wastewater heat pump varied less, which could be largely attributed to the stable- and hightemperature heat source. The "on" and "off" behaviors of the heat pumps during a day were obviously presented and the effects of intermittent or continuous operating modes on COPs were also illustrated, we found the variations of the energy performances of the wastewater and geothermal heat pumps during daily operation period, degradation phenomenon in COPs has observed corresponding to the largest temperature step took place at initial starting period. This effect could be attributed to the decreasing in the inlet temperature of the evaporator, which had lowered the heat extraction ability of the heat pump unit. 


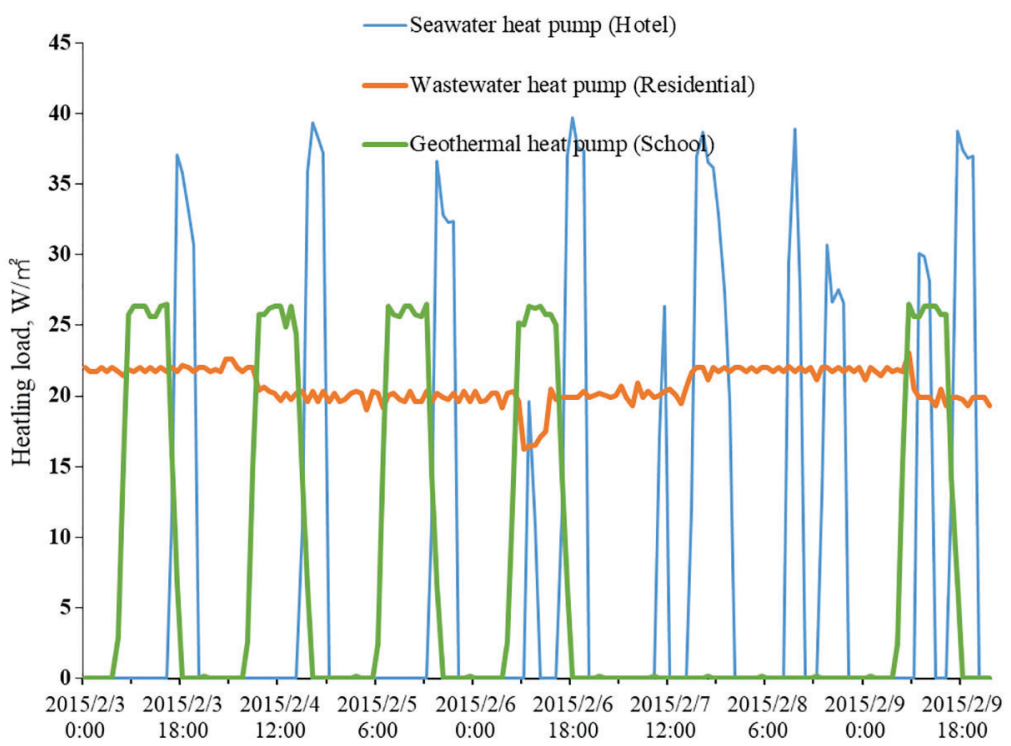

Figure 16: Hourly heating load profiles of different heat pump projects from 3th February to 9th February of 2015

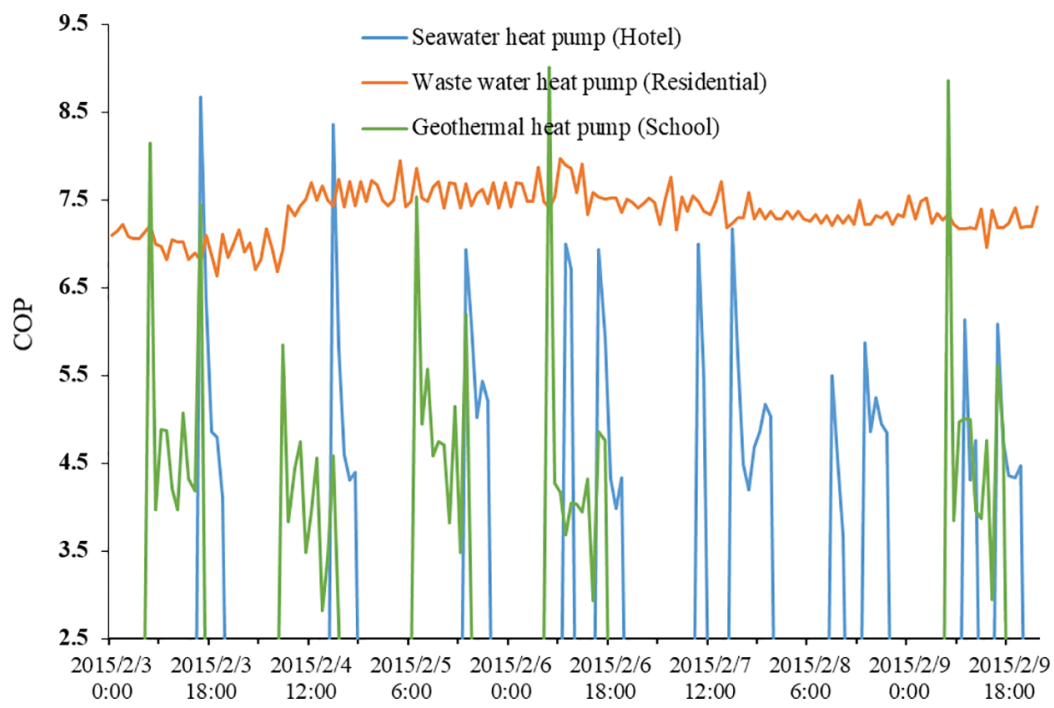

Figure 17: Hourly COPs of different heat pump units measured from 3th February to 9th February of 2015

\subsection{Discussion and Suggestion}

To reveal the effects of detailed operating conditions on energy performances of the heat pumps, the ranges of measured COPs of heat pump systems in correlation with the operational conditions were investigated as illustrated in Fig. 18. COPs were against with rising trend of outlet water temperature from the condenser. It could also obviously find the degradation in COP with decreasing in temperature of heat sources, COPs of the geothermal heat pump was more sensitive to the inlet temperature at evaporator, indicated importance of efficient thermal transfer design, such as optimal flow rate at ground side. Larger nominal capacity and stable heat source enabled the wastewater heat pump performed high energy efficiency, its energy efficiency was sensitive to operating conditions, including inlet temperature 
at evaporator and outlet temperature from the condenser. Less correlation of a geothermal heat pump's COPs with hot water supply temperature might be attributed to heat inertia and lower heating generating capacity. Energy performance of heat pump system was determined by the thermal quality of the heat source and detail operational conditions. COP distributions of different heat pump technologies under various operating conditions were calculated and depicted in Fig. 18. The x-axis represented the range of heat source supply temperature, $\mathrm{y}$-axis was the dimensionless in condenser supply temperature. Measured data points of the main heating period last from 22nd November to 15th March, COP color-scale range of specific heat pump unit was displayed on the right of the graph. The COPs was as a function of evaporator temperature lift for building space heating, it penalized more in wastewater and seawater heat pumps with relatively large capacity. The COPs of the heat pump illustrated inefficient choice under the operational conditions with a lower-temperature heat source and higher supply temperature to cover the heating load. The positive effect of the rising temperature of heat sources on improving the energy performance of heat pumps was more obvious when the heating supply temperature was higher.

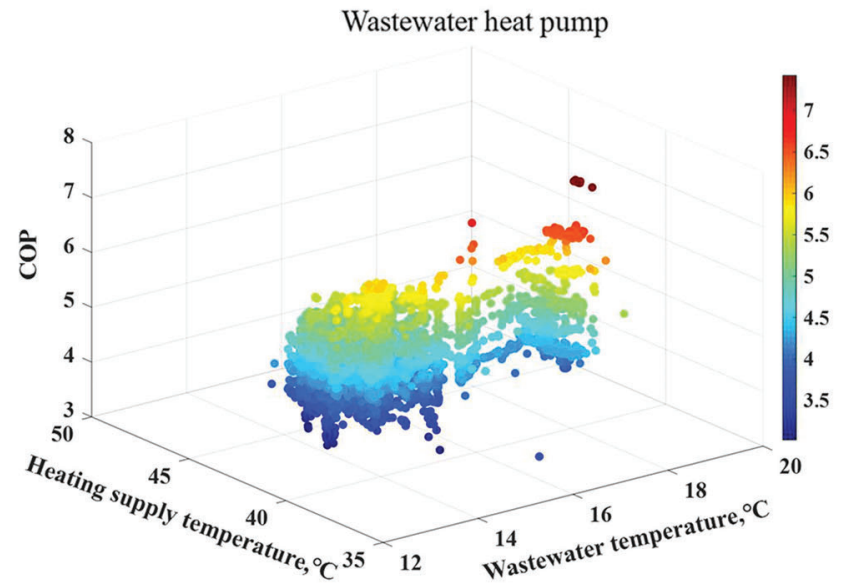

(a)

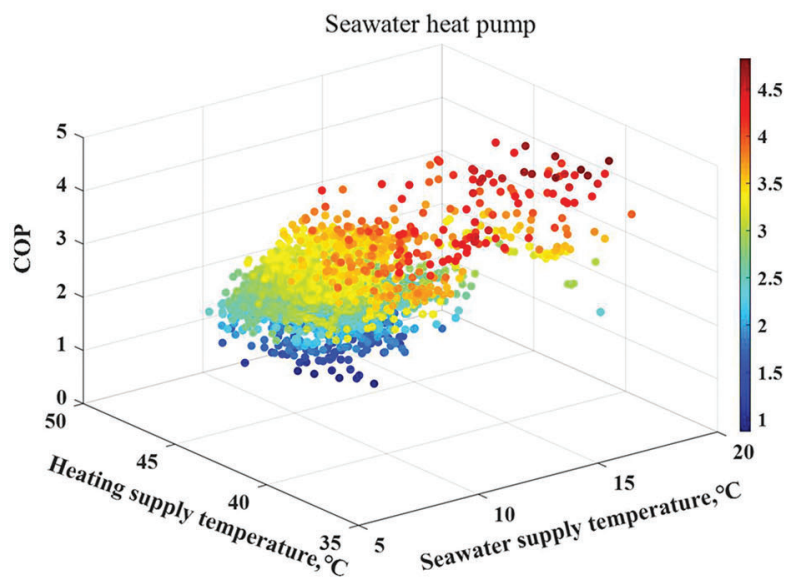

(b)

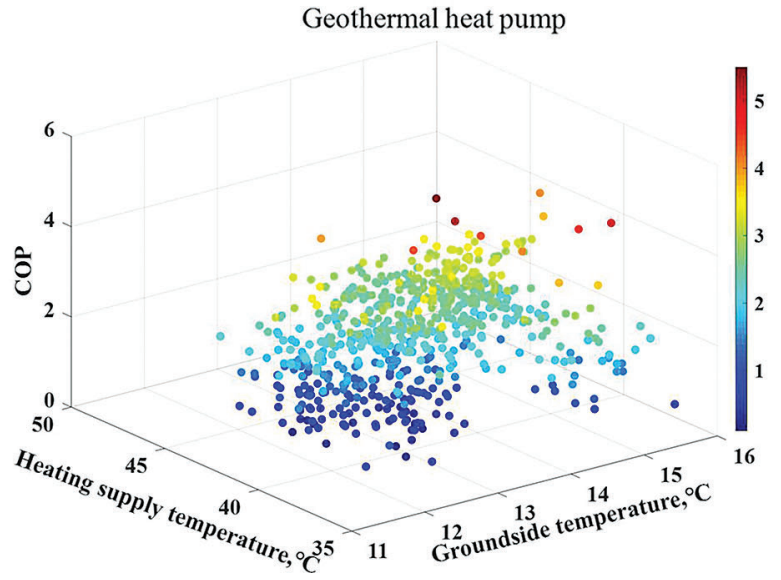

(c)

Figure 18: Distributions of unit COPs with temperature of heat source and hot water supply, (a) Wastewater heat pump, (b) Seawater heat pump and (c) Geothermal heat pump 
The net present value (NPV) performance of heat pump within assumed 20 years lifespan was calculated according to Eq. (3), discount rate $\mathrm{r}$ is 0.04 . The annual cash flow $C_{i}$ refers to the cost difference between electricity consumption and central heating supply mode, 43 yuan/Gj heat price is set based on the current energy market, $I_{0}$ presents the initial capacity cost, 2000 yuan $/ \mathrm{kW}$.

$N V P=\sum_{i=1}^{m} \frac{C_{i}}{(1+r)^{i}}-I_{0}$

Fig. 19 presents the NPV performances of heat pump systems under different operational scenarios taking account of annual operating hours, parameter COP value, heat pump capacity investment cost and electricity price. The cost feasibility scopes of heat pumps for space heating are outlined under different electricity price values. The attractiveness of efficient heat pumps arises with longer heating hours, the effect of the difference in capacity investment cost is relatively low in long-term performance. It is also concluded that heating load share among different customers can improve its cost competitiveness further, higher electricity price would limit economic feasibility of heat pump for space heating, cost-saving performance drops sharply for inefficient heat pump, especially under longer operating hours.
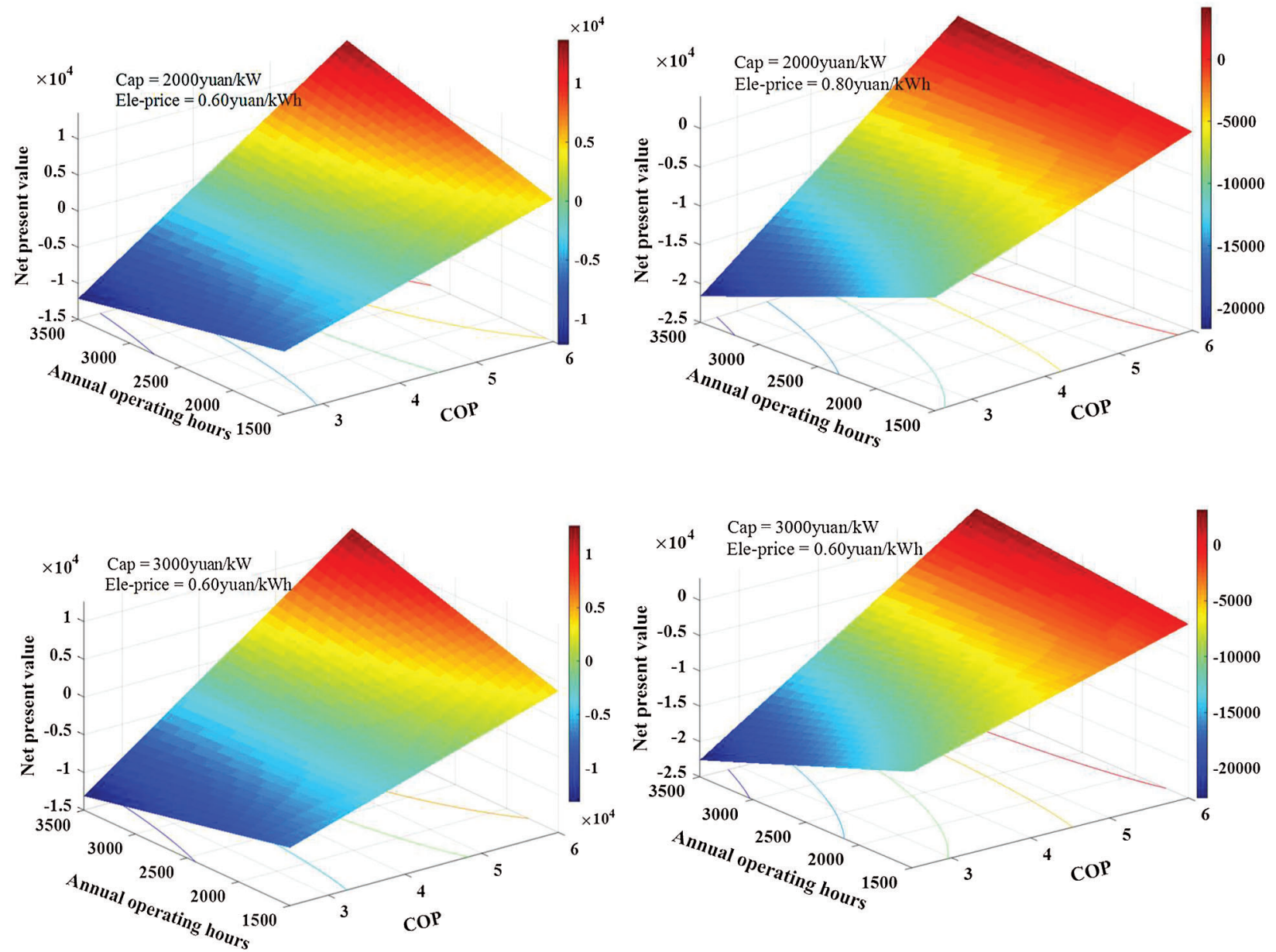

Figure 19: NPV performances of heat pump system under different electricity price and heat pump per capital costs 
From an economic point of view, the feasibility of the heat pump for building space heating is associated with heating supply temperature and its annual utilization factor. Building heating load share and efficient terminal heating devices selection would favor the cost competitiveness of heat pump as an alternative space heating solution, especially under transition towards ultra-low temperature heating supply system.

From the carbon emission reduction perspective, the annual $\mathrm{CO}_{2}$ reduction of heat pump per $\mathrm{kW}$ capacity can be calculated according to Eq. (4), $\mathrm{T}$ is the annual operational period, $f_{c o 2}^{H}$ is carbon emission intensity of conventional district central heating supply per GJ, $110 \mathrm{~kg} / \mathrm{MJ}$ [4]. $f_{c o 2}^{E}$ is carbon intensity of electricity per $\mathrm{kWh}$.

$C O_{r e}=C O P \cdot T \cdot 3.6 \cdot f_{c o 2}^{H}-T \cdot f_{c o 2}^{E}$

The detailed effects of annual operational hours, heat pump COP and $\mathrm{CO}_{2}$ intensity of electricity on the carbon emission reduction performance are illustrated in Fig. 20. Heat pumps can play as an effective approach to reduce the carbon emission in district building heating supply. Ensure of the longer operational period and improvement in COP improve the carbon reduction benefit considerably.
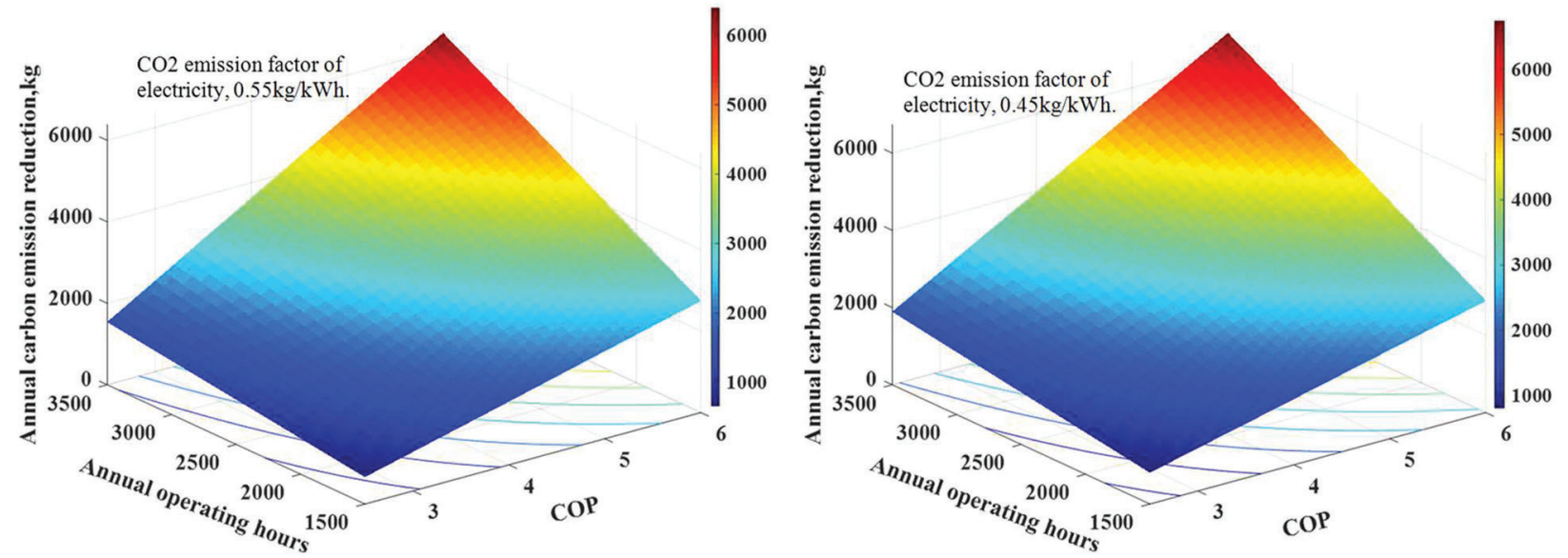

Figure 20: Annual $\mathrm{CO}_{2}$ reduction performance of heat pump per capacity under different scenarios

\section{Conclusions}

There is a transition towards low-temperature and clean heating supply in building space heating development. This study investigated the operational energy performances of different heat pump technologies for existing building space heating projects in Qingdao, China. The detailed dynamic behaviors of heat pump systems during the whole seasonal heating period were statistically exhibited and compared based on measurement data.

Firstly, measurement results compared the temperature range and fluctuations of the different low-grade heat sources including wastewater, seawater and geothermal heat sources. Statistical analysis presented that wastewater presented the highest average temperature and stable heat source during the whole heating season. Meanwhile, the results also revealed how the operational parameters and thermal characteristics of heat sources influenced the energy performances of the heat pumps.

The choice of the heat pump type has a significant impact on the energy efficiency of the building space heating projects. The operational performance of heat pump highly relies on the quality of heat sources, the temperature of the urban wastewater is generally above $15^{\circ} \mathrm{C}$, which enables the heat pump as efficient building space heating technology during the whole winter period, the measured COP value is over 7.0. 
Measurement provided evidence that COPs of seawater and geothermal heat pump highly depended on the dynamic heating extraction process, we observed an obvious degradation in time-series COP profile of heat pumps at their initial operating stage in response to the temperature drop of the heat source. The energy performances of heat pumps under various conditions were also examined, the decreasing hot water supply temperature was favorable for improving the competitiveness of the heat pump system for building space heating. The rising temperature of the heat source could efficiently reduce the degradation in COP when the heating supply temperature increases.

The NPV performances of the heat pump system were carried out, the result indicated that the longer operating hours would play a positive role in the economic feasibility of an energy-efficient heat pump system, the efforts towards the energy-efficient design of heat pump, and low-temperature indoor terminal heating devices application is favorable. The electrical heat pump can play a promising role in reducing building space heating related $\mathrm{CO}_{2}$, especially with a longer annual operating period.

The periodic occupant of buildings has a significant impact on the utilization factor of the heat pump system, we can see that commercial and school buildings generally feature with intermittent or shorter annual heating supply modes, in this respect heating load shares among aggregated different customers towards rising annual utilization ratio and introduction of a flexible price are possible options to shorten the payback period, offering improved energy and cost efficiency performance.

Author Contributions: Conceptualization, Yanxue Li and Yingjun Ruan; methodology, Weijun Gao; software, Yanxue Li; formal analysis, Xiaoyi Zhang; investigation, Xiaoyi Zhang and Wenya Xu; resources, Yingjun Ruan. and Yinzhong Wang. All authors have read and agreed to the published version of the manuscript.

Funding Statement: This research was funded by Development of the Healthy and Low-Carbon Residential House with Smart Home Environment Management System, Grant No. 2019GSF110003 and Research on the energy efficiency and health performance improvement of building operations based on lifecycle carbon emissions reduction Grant No. 2018YFE0106100. We gratefully acknowledge the help from ASSURAN International Scholarship Foundation.

Conflicts of Interest: The authors declare that they have no conflicts of interest to report regarding the present study.

\section{References}

1. Hong, T., Chen, Y., Luo, X., Luo, N., Lee, S. H. (2020). Ten questions on urban building energy modeling. Building and Environment, 168, 106508. DOI 10.1016/j.buildenv.2019.106508.

2. Vivian, J., Emmi, G., Zarrella, A., Jobard, X., Pietruschka, D. et al. (2018). Evaluating the cost of heat for end users in ultra low temperature district heating networks with booster heat pumps. Energy, 153, 788-800. DOI 10.1016/j. energy.2018.04.081.

3. China Association of Building Energy Efficiency (2020). China Building Energy Consumption Report 2019. https://www.cabee.org/.

4. Building Energy Conservation Research Center. (2020). Annual Report on China Building Energy Efficiency. https://www.china-heating.org.cn/.

5. Harris, G. P., (2017). China's Paris pledge on climate change: Inadequate and irresponsible. Journal of Environmental Studies \& Sciences, 7(1), 102-107. DOI 10.1007/s13412-017-0422-0.

6. Li, X., Li, W., Zhang, R., Jiang, T., Chen, H. et al. (2020). Collaborative scheduling and flexibility assessment of integrated electricity and district heating systems utilizing thermal inertia of district heating network and aggregated buildings. Applied Energy, 258, 114021. DOI 10.1016/j.apenergy.2019.114021. 
7. Du, M., Wang, X., Peng, C., Shan, Y., Chen, H. et al. (2018). Quantification and scenario analysis of $\mathrm{CO}_{2}$ emissions from the central heating supply system in China from 2006 to 2025. Applied Energy, 225, 869875. DOI 10.1016/j.apenergy.2018.05.064.

8. Wang, J., Zhou, Z., Zhao, J., Zheng, J., Guan, Z. (2019). Towards a cleaner domestic heating sector in China: Current situations, implementation strategies, and supporting measures. Applied Thermal Engineering, 152, 515-531. DOI 10.1016/j.applthermaleng.2019.02.117.

9. Xu, P., Xu, T., Shen, P. (2013). Energy and behavioral impacts of integrative retrofits for residential buildings: What is at stake for building energy policy reforms in northern China? Energy Policy, 52, 667-676. DOI 10.1016/j.enpol.2012.10.029.

10. Wu, D. (2019). Accountability relations and market reform in China's electric power sector. Global Transitions, 1, 171-180. DOI 10.1016/j.glt.2019.10.002.

11. Su, C., Madani, H., Liu, H., Wang, R., Palm, B. (2020). Seawater heat pumps in China, a spatial analysis. Energy Conversion and Management, 203, 112240. DOI 10.1016/j.enconman.2019.112240.

12. Zhang, S., Zhang, L., Zhang, X. (2017). Performance evaluation of existed ground source heat pump systems in buildings using auxiliary energy efficiency index: Cases study in Jiangsu, China. Energy and Buildings, 147, 90100. DOI 10.1016/j.enbuild.2017.04.052.

13. Qiao, Z., Long, T., Li, W., Zeng, L., Li, Y. et al. (2020). Performance assessment of ground-source heat pumps (GSHPs) in the Southwestern and Northwestern China: In situ measurement. Renewable Energy, 153, 214-227. DOI 10.1016/j.renene.2020.02.024.

14. Wirtz, M., Kivilip, L., Remmen, P., Müller, D. (2020). 5th generation district heating: A novel design approach based on mathematical optimization. Applied Energy, 260, 114158. DOI 10.1016/j.apenergy.2019.114158.

15. Østergaard, D. S., Svendsen, S. (2018). Experience from a practical test of low-temperature district heating for space heating in five danish single-family houses from the 1930s. Energy, 159, 569-578. DOI 10.1016/j. energy.2018.06.142.

16. Yang, X., Svendsen, S. (2018). Ultra-low temperature district heating system with central heat pump and local boosters for low-heat-density area: Analyses on a real case in Denmark. Energy, 159, 243-251. DOI 10.1016/j. energy.2018.06.068.

17. Wu, Z., Zhang, Y., Deng, N. (2019). Performance investigation of the heat pump and power generation integration system. International Journal of Energy Research, 43(14), 8608-8622. DOI 10.1002/er.4858.

18. Dannemand, M., Sifnaios, I., Tian, Z., Furbo, S. (2020). Simulation and optimization of a hybrid unglazed solar photovoltaic-thermal collector and heat pump system with two storage tanks. Energy Conversion and Management, 206, 112429. DOI 10.1016/j.enconman.2019.112429.

19. Zhang, S., Zhang, L., Wei, H., Jing, J., Zhou, X. et al. (2016). Field testing and performance analyses of ground source heat pump systems for residential applications in Hot summer and cold winter area in China. Energy and Buildings, 133, 615-627. DOI 10.1016/j.enbuild.2016.09.069.

20. Madonna, F., Bazzocchi, F. (2013). Annual performances of reversible air-to-water heat pumps in small residential buildings. Energy and Buildings, 65, 299-309. DOI 10.1016/j.enbuild.2013.06.016.

21. Maivel, M., Kurnitski, J. (2015). Heating system return temperature effect on heat pump performance. Energy and Buildings, 94, 71-79. DOI 10.1016/j.enbuild.2015.02.048.

22. Østergaard, P. A., Andersen, A. N. (2018). Economic feasibility of booster heat pumps in heat pump-based district heating systems. Energy, 155, 921-929. DOI 10.1016/j.energy.2018.05.076.

23. Xu, L., Li, E., Xu, Y., Mao, N., Shen, X. et al. (2020). An experimental energy performance investigation and economic analysis on a cascade heat pump for high-temperature water in cold region. Renewable Energy, 152, 674-683. DOI 10.1016/j.renene.2020.01.104.

24. Li, Y., Gao, W., Zhang, X., Ruan, Y., Ushifusa, Y. et al. (2020). Techno-economic performance analysis of zero energy house applications with home energy management system in Japan. Energy and Buildings, 214, 109862. DOI 10.1016/j.enbuild.2020.109862.

25. Szreder, M., Miara, M. (2020). Effect of heat capacity modulation of heat pump to meet variable hot water demand. Applied Thermal Engineering, 165, 114591. DOI 10.1016/j.applthermaleng.2019.114591. 
26. Zhang, Q., Zhang, L., Nie, J., Li, Y. (2017). Techno-economic analysis of air source heat pump applied for space heating in Northern China. Applied Energy, 207, 533-542. DOI 10.1016/j.apenergy.2017.06.083.

27. Ma, G. Y., Chai, Q. H., Jiang, Y. (2003). Experimental investigation of air-source heat pump for cold regions. International Journal of Refrigeration, 26(1), 12-18. DOI 10.1016/S0140-7007(02)00083-X.

28. Zhang, Y., Ma, Q., Li, B., Fan, X., Fu, Z. (2017). Application of an air source heat pump (ASHP) for heating in harbin, the coldest provincial capital of China. Energy and Buildings, 138, 96-103. DOI 10.1016/j. enbuild.2016.12.044.

29. Panaras, G., Mathioulakis, E., Belessiotis, V. (2014). A method for the dynamic testing and evaluation of the performance of combined solar thermal heat pump hot water systems. Applied Energy, 114, 124-134. DOI 10.1016/j.apenergy.2013.09.039.

30. Ran, S., Li, X., Xu, W., Wang, B. (2020). A solar-air hybrid source heat pump for space heating and domestic hot water. Solar Energy, 199, 347-359. DOI 10.1016/j.solener.2020.02.038.

31. Yu, S. (2018). Introduction of water source heat pump system. In: Wang, R., Zhai, X. (Eds.), Handbook of energy systems in green buildings, pp. 1-48. Berlin, Heidelberg: Springer.

32. Deng, J., Wei, Q., Liang, M., He, S., Zhang, H. (2019). Does heat pumps perform energy efficiently as we expected: Field tests and evaluations on various kinds of heat pump systems for space heating. Energy and Buildings, 182, 172-186. DOI 10.1016/j.enbuild.2018.10.014.

33. Kontu, K., Vimpari, J., Penttinen, P., Junnila, S. (2020). Individual ground source heat pumps: Can district heating compete with real estate owners' return expectations? Sustainable Cities and Society, 53, 101982. DOI 10.1016/j. scs.2019.101982.

34. Choi, W., Ooka, R., Nam, Y. (2018). Impact of long-term operation of ground-source heat pump on subsurface thermal state in urban areas. Sustainable Cities and Society, 38, 429-439. DOI 10.1016/j.scs.2017.12.036.

35. Zanchini, E., Lazzari, S., Priarone, A. (2012). Long-term performance of large borehole heat exchanger fields with unbalanced seasonal loads and groundwater flow. Energy, 38(1), 66-77. DOI 10.1016/j.energy.2011.12.038.

36. Zheng, W., Ye, T., You, S., Zhang, H. (2015). The thermal performance of seawater-source heat pump systems in areas of severe cold during winter. Energy Conversion and Management, 90, 166-174. DOI 10.1016/j. enconman.2014.10.050.

37. Jia, X., Duanmu, L., Shu, H. (2017). Effect of seawater intake methods on the performance of seawater source heat pump systems in cold climate areas. Energy and Buildings, 153, 317-324. DOI 10.1016/j.enbuild.2017.08.016.

38. Shu, H., Duanmu, L., Shi, J., Jia, X., Ren, Z. et al. (2015). Field measurement and energy efficiency enhancement potential of a seawater source heat pump district heating system. Energy and Buildings, 105, 352-357. DOI 10.1016/j.enbuild.2015.07.069.

39. Liu, L., Wang, M., Chen, Y. (2019). A practical research on capillaries used as a front-end heat exchanger of seawater-source heat pump. Energy, 171, 170-179. DOI 10.1016/j.energy.2019.01.012.

40. Im, P., Liu, X., Henderson, H. (2018). Operational performance characterization of a heat pump system utilizing recycled water as heat sink and heat source in a cool and Dry climate. Energies, 11(1), 211. DOI 10.3390/ en11010211.

41. Hepbasli, A., Biyik, E., Ekren, O., Gunerhan, H., Araz, M. (2014). A key review of wastewater source heat pump (WWSHP) systems. Energy Conversion and Management, 88, 700-722. DOI 10.1016/j.enconman.2014.08.065.

42. Bohlayer, M., Zöttl, G. (2018). Low-grade waste heat integration in distributed energy generation systems-An economic optimization approach. Energy, 159, 327-343. DOI 10.1016/j.energy.2018.06.095.

43. Zheng, J., Yu, Y., Li, J., Fu, C. H. (2013). Research on reclaimed water heat energy conditions and application in Beijing. Advanced Materials Research, 860-863, 728-732. DOI 10.4028/www.scientific.net/AMR.860-863.728.

44. Zajacs, A., Bogdanovics, R., Borodinecs, A. (2020). Analysis of low temperature lift heat pump application in a district heating system for flue gas condenser efficiency improvement. Sustainable Cities and Society, 57, 102130. DOI $10.1016 /$ j.scs.2020.102130. 